\title{
Multi-instrumented observations of the equatorial $F$-region during June solstice: large-scale wave structures and spread- $F$
}

\author{
Fabiano S. Rodrigues ${ }^{1 *}$ (D), Dustin A. Hickey², Weijia Zhan', Carlos R. Martinis², Bela G. Fejer ${ }^{3}$, Marco A. Milla ${ }^{4}$ \\ and Juan F. Arratia ${ }^{5}$
}

\begin{abstract}
Typical equatorial spread- $F$ events are often said to occur during post-sunset, equinox conditions in most longitude sectors. Recent studies, however, have found an unexpected high occurrence of ionospheric F-region irregularities during June solstice, when conditions are believed to be unfavorable for the development of plasma instabilities responsible for equatorial spread- $F$ (ESF). This study reports new results of a multi-instrumented investigation with the objective to better specify the occurrence of these atypical June solstice ESF in the American sector and better understand the conditions prior to their development. We present the first observations of June solstice ESF events over the Jicamarca Radio Observatory $\left(11.95^{\circ} \mathrm{S}, 76.87^{\circ} \mathrm{W}, \sim 1^{\circ}\right.$ dip latitude) made by a 14 -panel version of the Advanced Modular Incoherent Scatter Radar system (AMISR-14). The observations were made between July 11 and August 4, 2016, under low solar flux conditions and in conjunction with dual-frequency GPS, airglow, and digisonde measurements. We found echoes occurring in the pre-, post-, and both pre- and post-midnight sectors. While at least some of these June solstice ESF events could have been attributed to disturbed electric fields, a few events also occurred during geomagnetically quiet conditions. The late appearance (22:00 LT or later) of three of the observed events, during clear-sky nights, provided a unique opportunity to investigate the equatorial bottomside $F$-region conditions, prior to ESF, using nighttime airglow measurements. We found that the airglow measurements (630 nm) made by a collocated all-sky camera show the occurrence of ionospheric bottomside F-region perturbations prior to the detection of ESF echoes in all three nights. The airglow fluctuations appear as early as 1 hour prior to radar echoes, grow in amplitude, and then coincide with ESF structures observed by AMISR-14 and GPS TEC measurements. They also show some of the features of the so-called large-scale wave structures (LSWS) that have been detected, previously, using other types of observations and have been suggested to be precursors of ESF. The bottomside fluctuations have zonal spacings between 300 and $500 \mathrm{~km}$, are aligned with the magnetic meridian, and extend at least a few degrees in magnetic latitude.
\end{abstract}

Keywords: Equatorial spread-F, Equatorial F-region, Radar, AMISR, Airglow, June, Solstice, Large-scale wave structure

\section{Introduction}

Equatorial spread- $F$ (ESF) is the name given, for historical reasons, to signatures of ionospheric $F$-region irregularities observed by a variety of instruments (e.g., airglow cameras, radars, in situ sensors on rockets and satellites) at low magnetic latitudes (Woodman and La Hoz 1976;

\footnotetext{
*Correspondence: fabiano@utdallas.edu

'W. B. Hanson Center for Space Sciences, UT Dallas, 800 W. Campbell Rd, Richardson, TX, 75080, USA
}

Full list of author information is available at the end of the article
McClure et al. 1977; Kelley et al. 1982; Otsuka et al. 2004; Makela et al. 2004; Abdu et al. 2009). ESF irregularities, with scale sizes ranging from tens to hundreds of kilometers in the magnetic zonal direction and several degrees in latitude, are believed to be produced by the so-called ionospheric generalized Rayleigh-Taylor (GRT) interchange instability (Sultan 1996). More recently, it has been suggested that a collisional shear instability could also play an important role in ESF development and dynamics (Hysell and Kudeki 2004; Aveiro and Hysell 2010). Secondary 
plasma instabilities produce small-scale ionospheric irregularities with scale sizes as short as a few centimeters (Woodman 2009).

One of the most important parameters for the linear growth of the GRT instability is believed to be the $F$ region equatorial vertical plasma velocity driven by the background zonal electric field at the magnetic equator (e.g., Fejer et al. 1999). Around sunset hours, a prereversal enhancement (PRE) (Eccles et al. 2015) of the zonal electric field is often observed, which produces favorable conditions for the GRT instability growth. This explains the high occurrence of ESF after sunset and during equinoctial months when the sunset terminator and magnetic meridian are aligned in most longitude sectors. The alignment between the terminator and the magnetic meridian enhances the magnitude of the PRE (Abdu et al. 1981; Tsunoda 1985). A number of studies, however, have shown that ESF events can occur during June solstice, especially under low solar flux conditions (Patra et al. 2009; Li et al. 2011; Ajith et al. 2016). The appearance of these structures is intriguing since the amplitude of the PRE is extremely reduced during these conditions. A better understanding of the processes contributing to June solstice irregularities is a topic of current interest and investigation. In addition to the PRE, it is also believed that plasma fluctuations in the equatorial bottomside $F$-region could be responsible for the observed variability in ESF occurrence (Tsunoda et al. 2011). These plasma perturbations would provide initial perturbations (seed waves) that are amplified by the instability process and develop into the large-scale plasma depletions associated with ESF. It has been suggested that, when the initial perturbations have significant amplitudes, ESF can develop even under weak/absent PRE conditions (Abdu et al. 2009; Tsunoda et al. 2010).

Tsunoda and White (1981) reported the observations of wave-like structures in the bottomside ionosphere using electron density observations made by the steerable ARPA Long-Range Tracking and Instrumentation Radar (ALTAIR) incoherent scatter radar. The observed structures had zonal wavelengths of about $400-800 \mathrm{~km}$. Tsunoda and White (1981) also reported that these waves were amplified by the GRT instability growing into ESF depletions. More recently, Tsunoda (2005) revisited the observations presented by Tsunoda and White (1981) referring to the bottomside perturbations as large-scale wave structures (LSWS). More importantly, Tsunoda (2005) pointed out that LSWS could be responsible for the variability in ESF and that unambiguous measurements of LSWS are needed to better understand its role in ESF.

Due to its fixed location and priority to other applications, ionospheric observations with ALTAIR are limited. Therefore, current research efforts include the development of adequate ways of specifying the variability of the bottomside $F$-region ionosphere at low latitudes (Saito and Maruyama 2007; Thampi et al. 2009; Tulasi Ram et al. 2012). Ongoing research efforts also include obtaining observational evidence of the causal relationship between the initial perturbations and ESF development (Tulasi Ram et al. 2014). The only other low-latitude incoherent scatter radar, located at the Jicamarca Radio Observatory in Peru, does not have steering capability and therefore cannot provide unambiguous observations of the bottomside electron density disturbances. Recent observational efforts have focused on obtaining information about these waves from their signatures in the total electron content (TEC) measurements (Thampi et al. 2009; Tulasi Ram et al. 2014). The TEC measurements are made using coherent beacon signals transmitted by low Earth orbit (LEO) satellites and received by ground-based receivers.

Here we present results of the first investigation on the occurrence of June solstice ESF events in the American (Peruvian) sector using an UHF radar system. Using a collocated all-sky airglow camera, we also investigate the state of the bottomside $F$-region prior to ESF. The measurements were made during a campaign of observations carried out between July 11 and August 4, 2016. The intensity of the red line $(630 \mathrm{~nm})$ emission measured by the all-sky camera is proportional to plasma density at bottomside $F$-region heights. Contamination by daytime airglow and weak emission caused by the high altitude of the $F$ layer around sunset, however, makes nighttime measurements prior to typical, early night ESF events extremely difficult. During the campaign, we detected three ESF events with echoes appearing late in the night, well after the PRE time. These events provided a unique opportunity, with adequate airglow measurement conditions, to study the bottomside $F$-region dynamics prior to ESF development.

This report is organized as follows: the "Methods/ Experimental" section provides information about the instrumentation and analyses of the measurements used in this study. The "Results" section presents our observational results. We discuss the results in the "Discussion" section, and in the "Conclusions" section, we summarize our main findings.

\section{Methods/Experimental}

The measurements used in this study were made using instruments located at the Jicamarca Radio Observatory (JRO) $\left(11.95^{\circ} \mathrm{S}, 76.87^{\circ} \mathrm{W}, \sim 1^{\circ}\right.$ dip latitude) in Peru. A campaign of 20 full-night (18:00 LT to 07:00 LT) observations was carried out between July 11 and August 4, 2016. The observations were made during a period of low solar flux conditions when unusual post-midnight June solstice ESF were reported to be observed by VHF radar systems located in other longitude sectors (e.g., Patra et al. 2009; 
Li et al. 2011; Yokoyama et al. 2011; Ajith et al. 2015). The average F10.7 index for the months of July and August 2016 was 88 SFU. The main instruments used in this study were a UHF radar system (AMISR-14) and an all-sky airglow camera system. Auxiliary measurements were made by a digisonde and by a ground-based dual-frequency GPS receiver.

\section{AMISR-14}

We used coherent backscatter radar measurements to monitor the genesis, development, and decay of ESF events. Two radars were available during our campaign of observations: the JULIA mode of the VHF Jicamarca radar and the 14-panel version of the UHF Advanced Modular Incoherent Scatter Radar (AMISR-14) system. For this investigation, we used measurements made by the AMISR-14 system because of its beam steering capability and because of gaps in JULIA's observations.

AMISR-14 is a modular, transportable phased-array radar system for ionospheric studies (Rodrigues et al. 2015; Hickey et al. 2015). For this campaign, we set operations in a new east-west scanning mode that attempted to produce a better description of the spatial distribution of $F$-region scattering structures than those produced by Rodrigues et al. (2015). AMISR-14 made observations at 10 different beam directions in the magnetic equatorial plane.

Table 1 summarizes the main radar parameters used for the AMISR-14 observations. Table 2 lists the pointing directions of the observations.

\section{All-sky camera}

Optical observations of nighttime airglow were carried out using an all-sky imaging camera that is collocated with the Jicamarca radar. The camera is positioned about $\sim 1.5 \mathrm{~km}$ to the east of the radar site. The camera has four filters for observations of different nighttime airglow

Table 1 AMISR-14 experiment parameters

\begin{tabular}{ll}
\hline Parameter & Value \\
\hline Frequency & $445 \mathrm{MHz}$ \\
Bragg wavelength & $0.34 \mathrm{~m}$ \\
Panel configuration & $7(\mathrm{NS}) \times 2(\mathrm{EW})$ \\
Antenna HPBW (NS/EW) & $2^{\circ} / 8^{\circ}$ \\
Peak power & $174 \mathrm{~kW}$ \\
Inter-pulse period (IPP) & $937.5 \mathrm{~km}$ \\
Number of beam positions & 10 \\
Code length & $28 \mathrm{bauds}$ \\
Baud length & $3 \mathrm{~km}$ \\
Coherent integration & None \\
Incoherent integration & 320 \\
\hline
\end{tabular}

Table 2 AMISR-14 pointing directions

\begin{tabular}{lll}
\hline Position & Azimuth (deg.) & Elevation (deg.) \\
\hline 1 & -90 & 69.2 \\
2 & -90 & 74.2 \\
3 & -90 & 80.4 \\
4 & -90 & 85.2 \\
5 & 0 & 90.0 \\
6 & 90 & 85.2 \\
7 & 90 & 80.4 \\
8 & 90 & 74.0 \\
9 & 90 & 69.2 \\
10 & 90 & 64.4 \\
\hline
\end{tabular}

emissions (at 557.7, 630.0, 695.0, and 777.4 $\mathrm{nm}$ ) and one filter for estimation of background emission (at $605.0 \mathrm{~nm}$ ). Additional details about this system can be found in Hickey et al. (2015).

For this study, we focused on measurements of the $630.0 \mathrm{~nm}$ (red line) emission caused by the relaxation of the $\mathrm{O}\left({ }^{1} \mathrm{D}\right)$ metastable state $\left(\mathrm{O}\left({ }^{1} \mathrm{D}\right) \rightarrow \mathrm{O}\left({ }^{3} \mathrm{P}\right)+h v\right.$ $(630.0 \mathrm{~nm})) . \mathrm{O}\left({ }^{1} \mathrm{D}\right)$ is produced by dissociative recombination of $\mathrm{O}_{2}^{+}\left(\mathrm{O}_{2}^{+}+\mathrm{e}^{-} \rightarrow \mathrm{O}\left({ }^{1} \mathrm{D}\right)+\mathrm{O}\left({ }^{3} \mathrm{P}\right)+4.99 \mathrm{eV}\right)$. The $\mathrm{O}_{2}^{+}$ions, however, are produced by charge exchange between $\mathrm{O}^{2}$ and $\mathrm{O}^{+}\left(\mathrm{O}^{2}+\mathrm{O}^{+} \rightarrow \mathrm{O}_{2}^{+}+\mathrm{O}\right)$. The peak of the volumetric emission rate occurs in the bottomside $F$-region and is proportional to the product between $\mathrm{O}^{+}$ and $\mathrm{O}_{2}$ densities. Therefore, variations in ion density at bottomside $F$-region heights will produce corresponding variations in airglow intensity. The two-dimensional airglow images captured by the all-sky camera allow us to distinguish temporal and spatial variations. We expected, for instance, that large-scale wave structures (Tsunoda and White 1981) such as those observed by ALTAIR would produce zonal fluctuations in the $630 \mathrm{~nm}$ emission.

For the observations available for this study, the total exposure for the red line emission was 120 seconds, and the total time for a full rotation of the filters was approximately 8 minutes. Therefore, one $630.0 \mathrm{~nm}$ image is obtained every 8 minutes. The $777.4 \mathrm{~nm}$ observations would have given us additional information about the dynamics of the $F$-region. Weak 777.4 nm intensities associated with the low equatorial ionospheric densities, however, precluded us from obtaining useful information from these observations at this time.

\section{Results}

Radar results

Figure 1 shows the range-time-intensity (RTI) maps of the $F$-region echoes detected by AMISR-14 on each night of the observation campaign. The RTI maps are for the beam pointed vertically and show that $F$-region echoes 

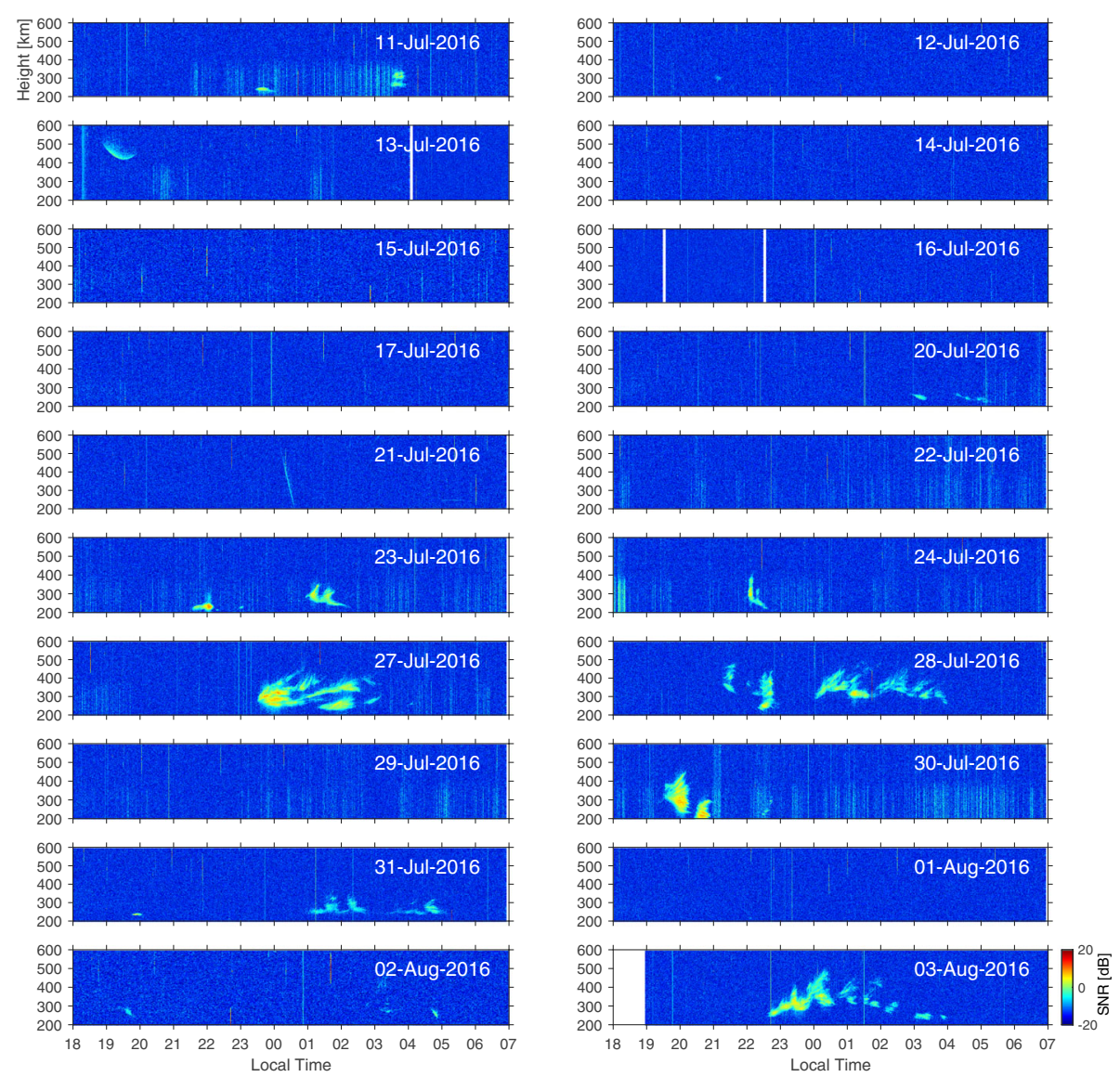

Fig. 1 Range-time-intensity (RTI) maps of the AMISR-14 observations made during the observation campaign (July 11-August 4, 2016). The RTI maps are for the vertical beam. The date in the upper right corner of each panel refers to the starting day of the observation

occurred on most nights after July 22. In particular, vertically developed echoing structures that started late in the night were observed on July $24-25$, July $27-28$, and August 3-4. Coincidentally, the observations were made during moon phases that are adequate for nighttime airglow measurements. The moon phase varied from Third Quarter on July 26 to New on August 2.

The RTI maps in Fig. 1 showed echoing structures starting much later than typical ESF. Typical ESF echoes start between 19:00 and 20:00 LT and last until about 23:0024:00 LT, depending on season and solar flux conditions (Hysell and Burcham 2002; Chapagain et al. 2009; Smith et al. 2015). The echoing structures observed on July 24-25, July 27-28, and August 3-4 first appeared around 22:00 LT, 23:45 LT, and 22:45 LT, respectively. The structures of July 27-28 and August 3-4 lasted several hours after local midnight. The late appearance of echoes provide an opportunity to use airglow measurements to investigate the $F$-region conditions in the magnetic equatorial region leading to ESF development. Two-dimensional AMISR14 observations using beams pointed in multiple directions in the magnetic equatorial plane indicate that the vertically developed echoing structures associated with fully formed ESF events formed around the radar site. Processing of the airglow measurements show good images with mostly clear skies (no clouds) for the three nights cited above.

\section{On geomagnetic activity during observations}

Figure 2 shows an expanded version of the RTIs for July 24-25, July 27-28, and August 3-4. In order to provide information about geomagnetic conditions under which the measurements were made, Fig. 2 also shows the temporal variation of the auroral electrojet (AE) index below each RTI map. During and after geomagnetically disturbed conditions, equatorial electric fields can deviate severely from their typical pattern mostly due to prompt penetration and disturbance dynamo effects (Fejer 2011; Fejer et al. 2017). They could drive upward plasma drifts in the nighttime sector, when drifts are typically downward, and destabilize the equatorial $F$-region. Short time scale (from minutes to 1-2 hours) variations are caused by prompt penetration electric fields of magnetospheric origin, which drive upward plasma drifts from about sunrise 


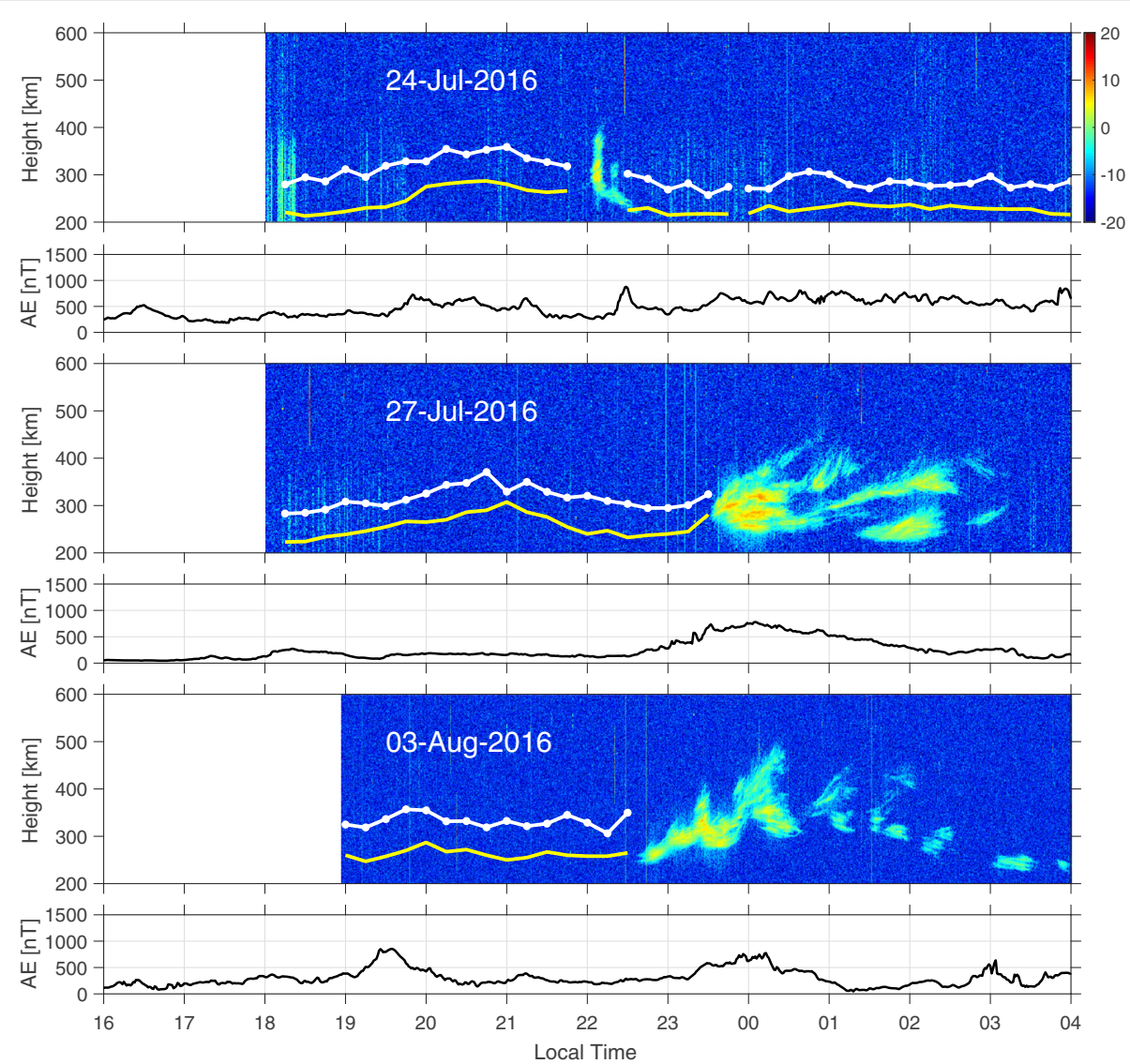

Fig. 2 RTI maps for July 24-25, July 27-28, and August 3-4, 2016. Digisonde estimates of hmF2 (white line with markers) and h'F (solid yellow line) are also shown. The auroral electrojet (AE) index is also shown, below each RTI map

to sunset and downward drifts at night. Longer lasting (few hours) plasma drift variations occurring a few hours after the onset of high latitude magnetic disturbances, as indicated by the $\mathrm{AE}$ index for example, are due to disturbance dynamo effects driven by enhanced energy deposition into the high altitude ionosphere (Blanc and Richmond 1980; Scherliess and Fejer 1997). Disturbance dynamo effects drive downward plasma drifts during the day and upward drifts at night and can last up to about 30 hours after geomagnetic active times (Fejer et al. 2017).

In order to provide more information about the $F$ region conditions over Jicamarca during our measurements, we also show the height of the $F$-region peak (hmF2) and the virtual height of the bottomside $F$ region ( $\left.h^{\prime} \mathrm{F}\right)$ as estimated by a collocated digisonde. The digisonde measurements show clear but modest increases in h'F and hmF2 around 21:00 LT on July 24 and 27. A sudden increase in h'F and hmF2 can also be noticed a few minutes prior to detection of the first echoes on July 27. This rapid rise in $F$-region height is likely to be caused by prompt penetration electric fields associated with the surge in auroral activity that can be seen in the $\mathrm{AE}$ index starting around 23:00 LT.
The digisonde measurements show only a small increase in h'F and hmF2 around 20:00 LT on August 3 compared to previous days. While weaker upward $F$-region uplifts were observed on this day, the layer did not return to lower heights ( $\mathrm{h}^{\prime} \mathrm{F} \sim 250 \mathrm{~km}$ ) as it was observed on the other 2 days. This behavior could have been driven by disturbance electric fields associated with large $\mathrm{AE}$ indices observed between 16:00 LT on August 2 and 14:00 LT on August 3 (not shown here) and the AE surge around 19:30 LT on August 3.

It will be shown, later on this report, that irregularity drifts were westward at the beginning of the ESF event on this night, which confirms the effects of disturbance electric fields.

For the sake of completeness, Fig. 3 shows the temporal variation of the $\mathrm{AE}$ index for all the days of our observation campaign. Note that we show the $\mathrm{AE}$ index starting at 00:00 LT of the day when observations started. It serves to show that high-latitude geomagnetic disturbances were present during the period of the campaign, which could have driven low-latitude disturbance electric fields. These fields could have provided conditions that were favorable for the development of at least some of the June solstice 

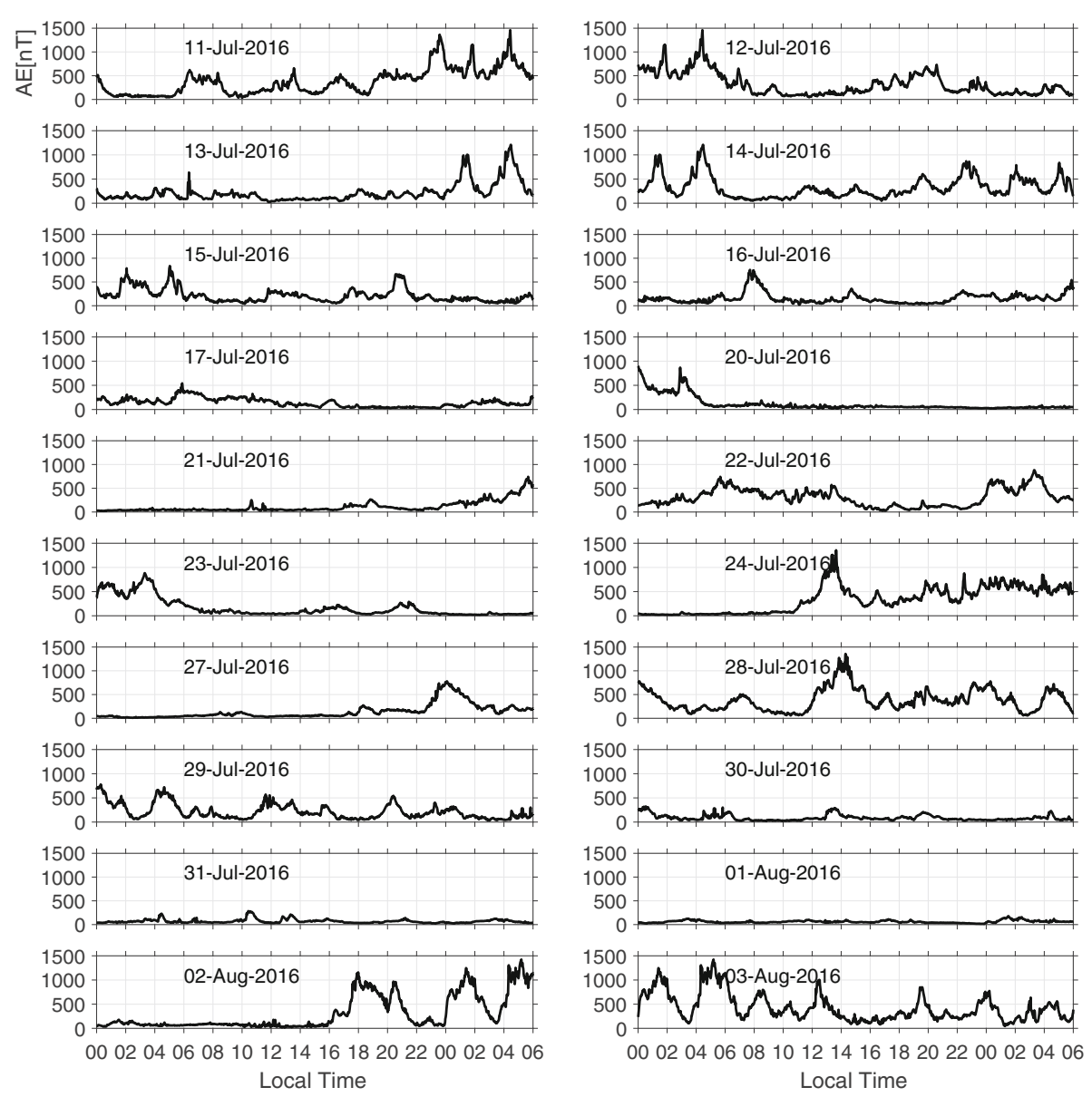

Fig. 3 The auroral electrojet (AE) index for each observation day of the campaign period. The starting date is indicated in each panel. Note the difference in the time axes with respect to Fig. 1

ESF events observed in our campaign. Comparing Figs. 1 and 3, we also find that ESF was observed even during geomagnetically quiet days as well. For instance, the $\mathrm{AE}$ index shows quiet conditions on July 30 and July 31 when pre- and post-midnight $F$-region echoes were observed by AMISR, respectively.

\section{Airglow results}

Figures 4, 5, and 6 summarize our comparisons between airglow features and radar observations for July 24-25, July $27-28$, and August $3-4$, respectively. The top panel in each figure shows the RTI map (vertical beam) for the night being analyzed. Analyses of the multi-beam observations made by AMISR-14 indicate that the observed plumes developed near the radar site and, therefore, are driven by local conditions. An example of the twodimensional evolution of a plume, as observed by AMISR14, is shown (Figs. 7 and 8 ) and discussed later in the text. The bottom panels show the $630 \mathrm{~nm}$ airglow images for the times indicated by vertical red lines on the RTI map. The airglow emission is mapped to geographic latitude versus longitude coordinates assuming a mean emission height of $250 \mathrm{~km}$. While this height might not be accurate, it does not affect our analysis and interpretation of the observations. In addition to the two-dimensional images (gray tones), we also show the mean zonal variation of the airglow intensity, around the latitude of the observation site $\left(\sim-12^{\circ} \mathrm{N}\right)$, as a red solid line curve. This curve has been added to the images to help the reader to identify the intensity fluctuations we refer to throughout the text. The location of the radar site is indicated by a green " + " sign in the center of the airglow images.

\section{Event 1: July 24-25, 2016}

Figure 4 shows our radar-airglow comparisons for July 24-25, 2016. The most striking feature of the first airglow images (top two rows) is the appearance of a faint dark band (region of low airglow emission) aligned in the north-south (NS) direction. We interpret this band as being produced by a small amplitude electron density perturbation in the bottomside $F$-region. The band precedes the appearance of ESF radar echoes. 


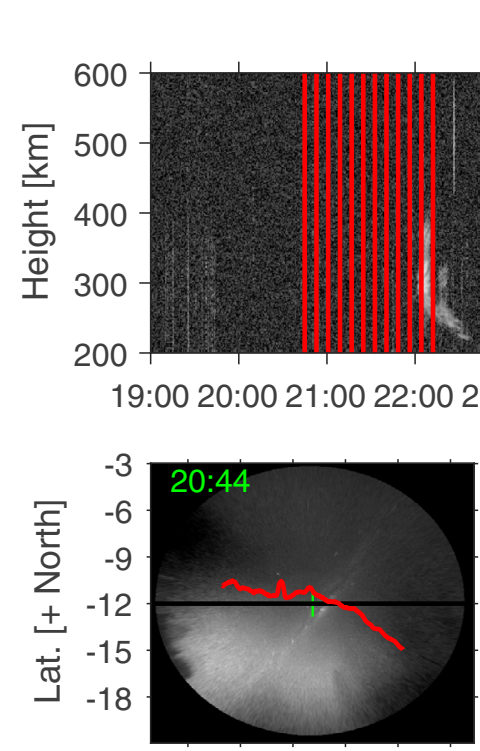

$-84-81-78-75-72-69$

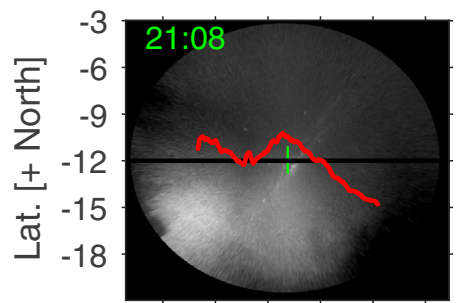

$-84-81-78-75-72-69$

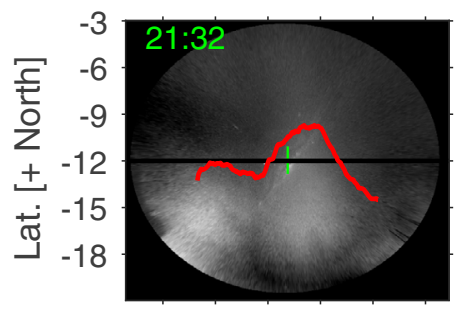

$-84-81-78-75-72-69$

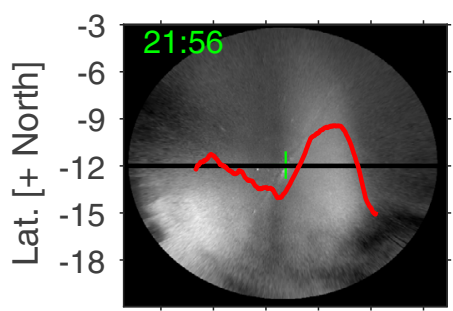

$-84-81-78-75-72-69$

Lon. [+ East]

\section{4-Jul-2016 - SNR [dB]}
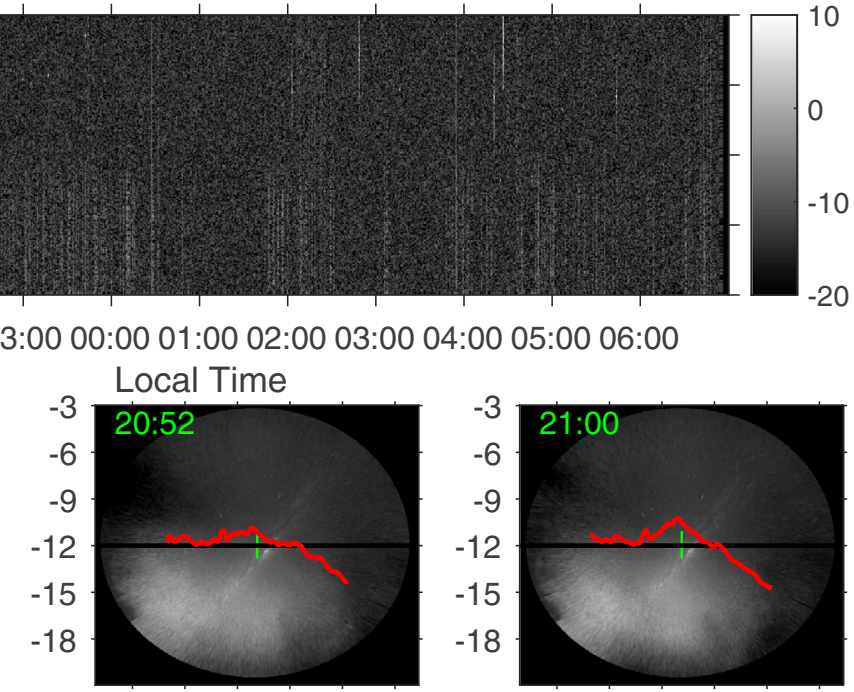

$-84-81-78-75-72-69$

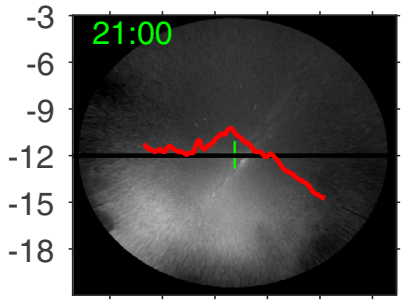

$-84-81-78-75-72-69$

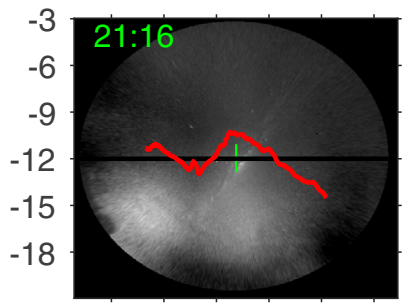

$-84-81-78-75-72-69$

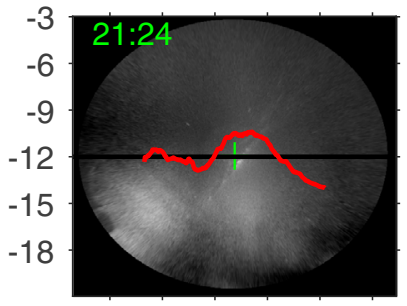

$-84-81-78-75-72-69$

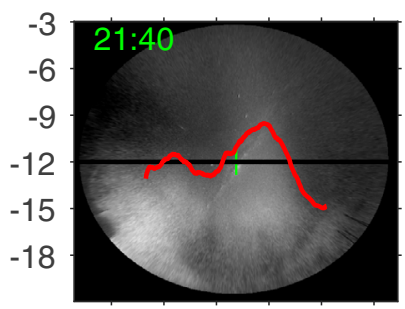

$-84-81-78-75-72-69$

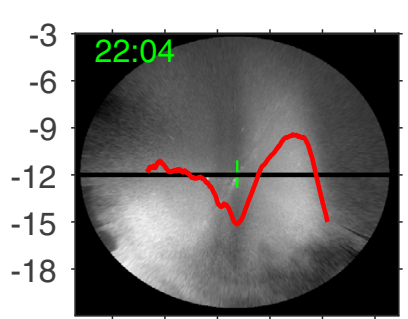

$-84-81-78-75-72-69$

Lon. [+ East]

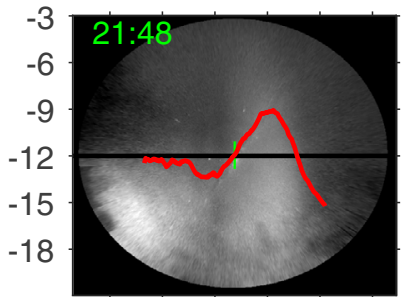

$-84-81-78-75-72-69$

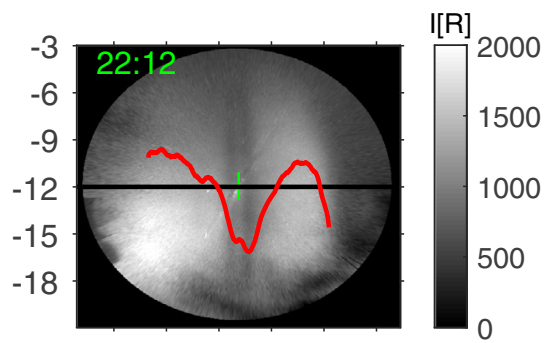

$-84-81-78-75-72-69$

Lon. [+ East]

Fig. 4 The top panel shows the RTI map for AMISR-14 observations (vertical beam) made on the night of July 24-25, 2016. The bottom panels show $630 \mathrm{~nm}$ airglow images (intensity in Rayleighs) for different times before and during the occurrence of ESF echoes. The times for each image are indicated in the top left side of each panel and as vertical green lines in the RTI map. The solid red line in each image represents the zonal variation of the airglow near the Jicamarca's latitude $\left(\sim-12^{\circ} \mathrm{N}\right)$. The black solid line is a reference base line to help the reader identify fluctuations in airglow if any 


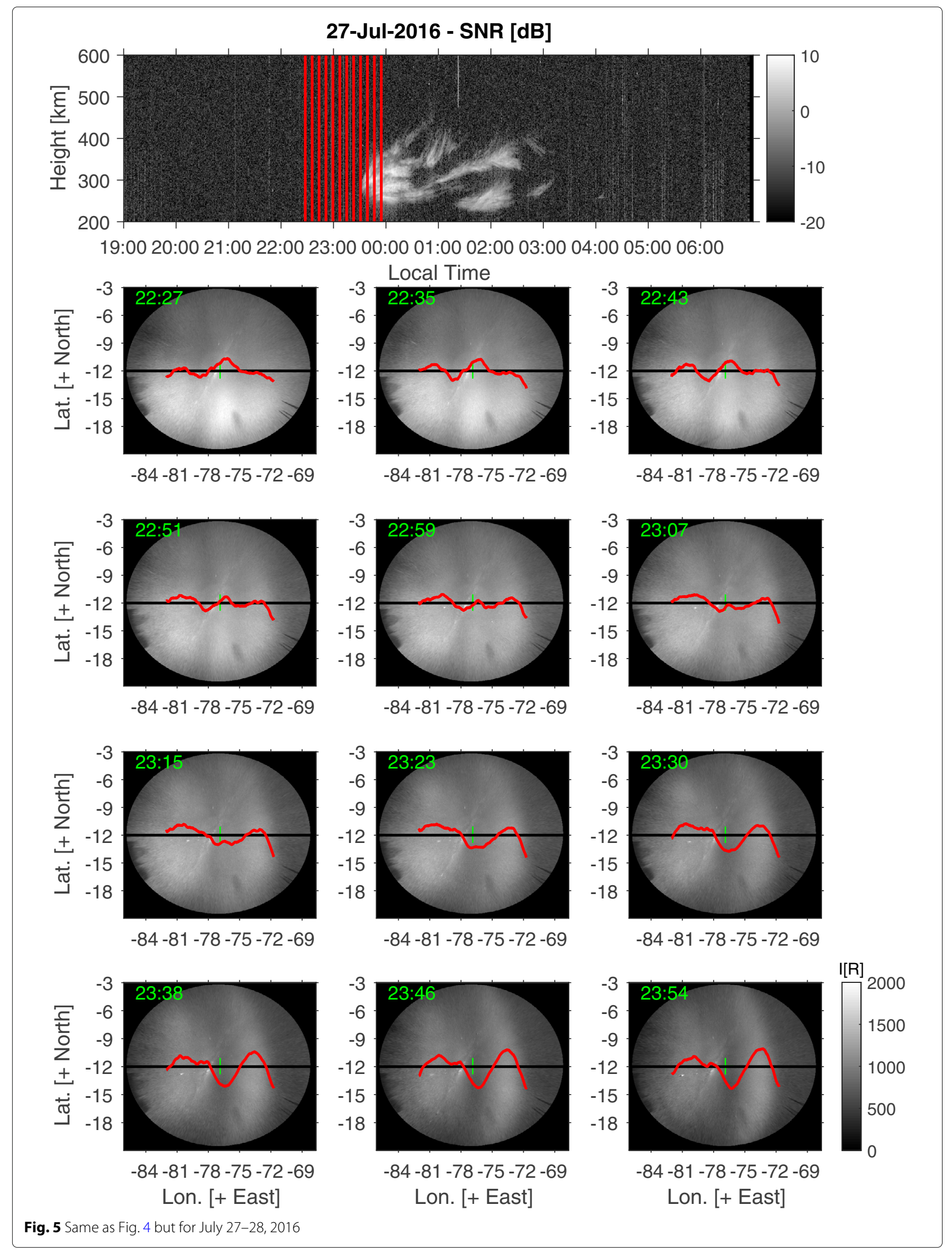




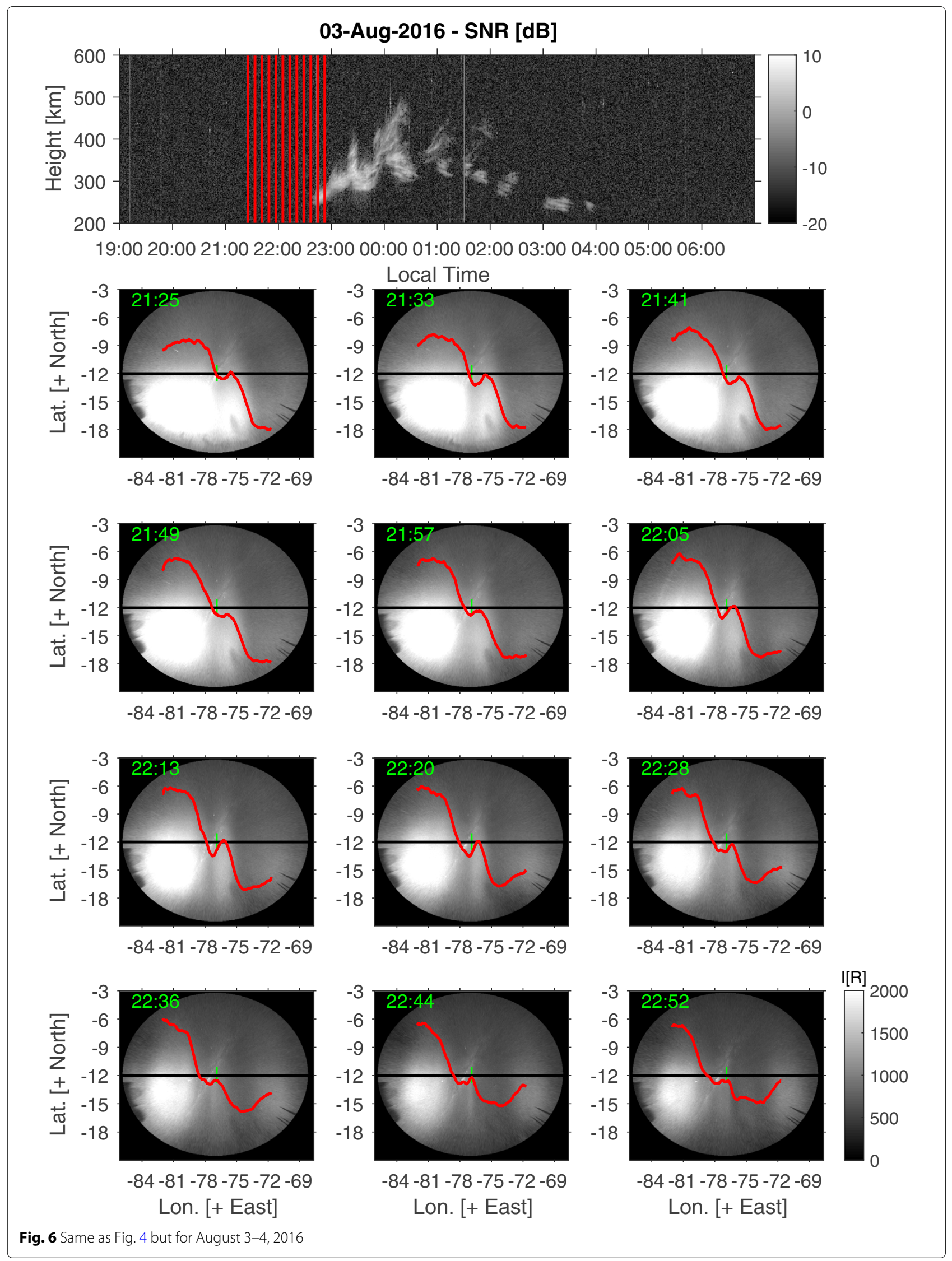



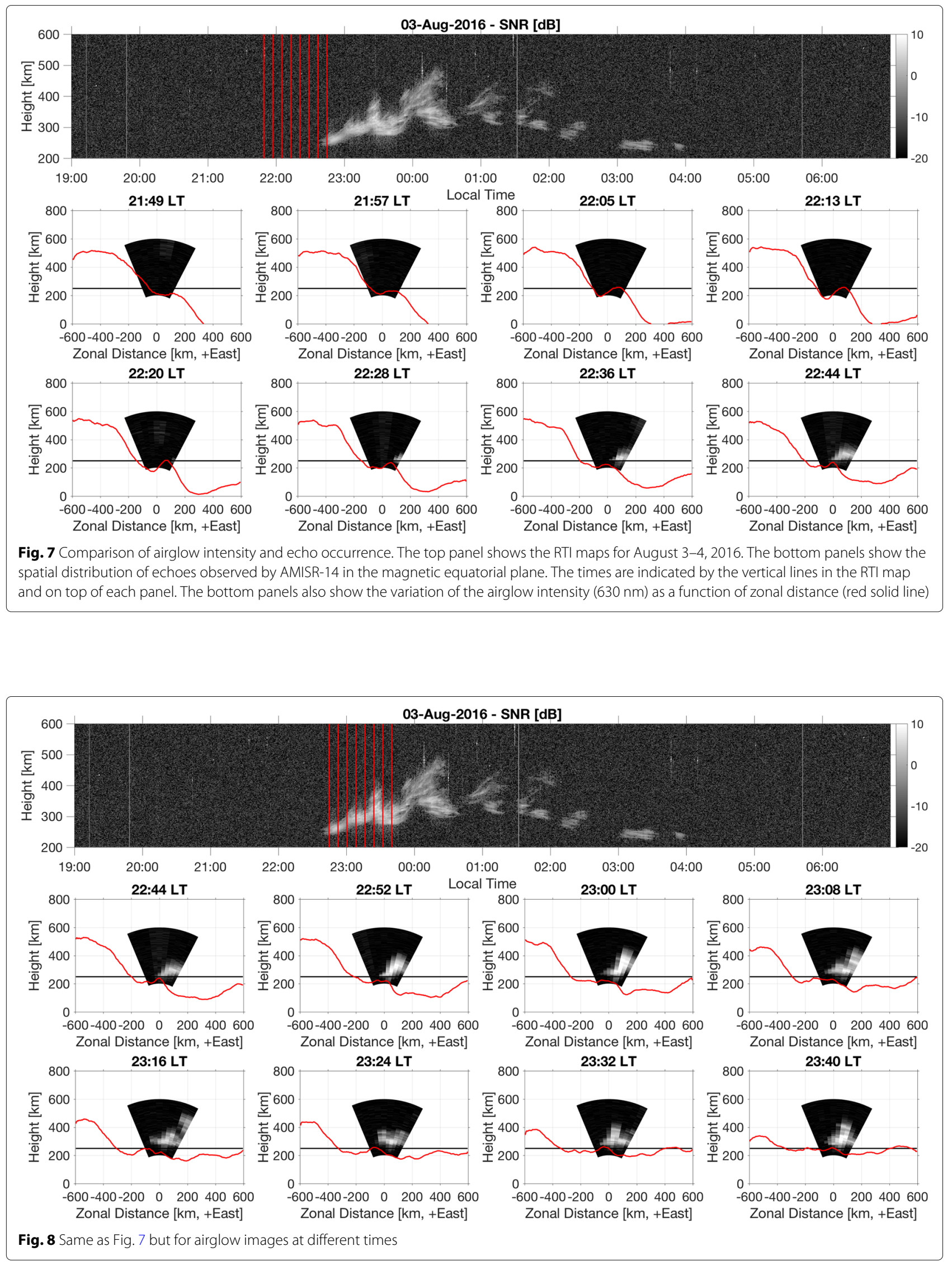
At 21:08 LT, this faint dark band is located to the west of the radar site, around $-79.5^{\circ} \mathrm{E}$. At $21: 48 \mathrm{LT}$, the band is located at $-78^{\circ} \mathrm{E}$. Therefore, the sequence of images indicates an eastward motion of approximately $72 \mathrm{~m} / \mathrm{s}$.

By 21:56 LT, the single dark band becomes more structured. Two thin dark bands, spaced by less than $150 \mathrm{~km}$ in the zonal direction, can now be distinguished in the images (between approximately $-76^{\circ}$ and $-78^{\circ} \mathrm{E}$ ). The increase in the amplitude of the airglow dark bands suggests the development of ESF plasma depletions (radar plumes).

The sequence of observations can be interpreted in terms of the processes described by Tsunoda (1983). The initial faint dark band is produced by a small amplitude electron density perturbation in the bottomside $F$-region. This density perturbation is, presumably, a result of the bottomside height modulation (upwelling) such as those observed by the ALTAIR radar (Tsunoda 1983). With time, the airglow perturbation grows in amplitude indicating an amplification of the bottomside density perturbation. Two strong dark bands start to be observed around 21:56 LT. They are optical signatures of ESF structures that developed in the initial upwelling. The easternmost dark band would be the optical signature of a primary ESF depletion. The second dark band would be the result of a secondary plume that is known to develop in the western wall of the initial bottomside upwellings caused by a wind-driven gradient drift instability. A close look at the RTI map for that night confirms the appearance of a primary plume followed by a secondary echoing structure. The tilt of the bottom portion of the scattering layer in the RTI map also supports the inferences above.

\section{Event 2: July 27-28, 2016}

Figure 5 now shows the airglow observations for the night of July 27-28. The format of Fig. 5 is the same of Fig. 4. In this case, the first airglow images show two initial faint dark bands that are, again, well aligned in the NS direction and spaced by about $3^{\circ}(350 \mathrm{~km})$ in longitude. For instance, at 22:43 LT, one band is located to the west of the radar site, around $-78^{\circ} \mathrm{E}$. The other band is located to the east, at about $-75^{\circ} \mathrm{E}$.

Like the case of July 24-25, the bands move in the eastward direction. By 23:23 LT, the two bands seemed to have merged producing the single, low-intensity airglow band right above the radar site. Also, the airglow intensity over the entire field of view of the all-sky camera seems to have decreased. This is consistent with the sudden uplift of the $F$-region shown by the digisonde around 23:15 LT (see h'F for July 27 in Fig. 2). The amplitude of the airglow band also increased.

The radar observations, however, show that no echoes are detected by the vertical beam until about 23:35 LT.

\section{Event 3: August 3-4, 2016}

Figure 6 shows our third example of airglow-radar observations. It shows results of measurements made on August 3-4, 2016.

Like in the previous cases, the first images show the occurrence of two faint airglow perturbations. For instance, at 21:41 LT, one perturbation is located around $-77^{\circ} \mathrm{E}$ and the other is located at around $-73^{\circ} \mathrm{E}$. The zonal spacing between the faint airglow depletions is about $4^{\circ}$ or $460 \mathrm{~km}$. In this case, one of the perturbations (the easternmost) is already located right above the radar site while no radar echoes were observed. This provides additional experimental evidence indicating that the faint airglow perturbations are not produced by a welldeveloped ESF structure (bubble or plume) but, like in the previous cases, are optical signatures of ESF precursors. While cases of ionospheric depletions without radar echoes are possible (e.g., Saito et al. 2008), most generally meter-scale irregularities are generated during the turbulent, development phase of plasma bubbles (e.g., Rodrigues et al. 2004). Furthermore, our interpretation of the airglow observations as signatures of ESF precursors is supported by the collocated GPS measurements of the ionospheric total electron content (TEC). Depletions in TEC are also only observed after about 23:00 LT when radar echoes reach the main $F$-region and topside as discussed later in this report. Measurements of TEC depletions are examined in more detail in the "Discussion" section.

For this event, the sequence of images show a weak westward motion of the airglow perturbations. The observations made on this night followed a surge in highlatitude geomagnetic disturbances as shown in Fig. 2, and as suggested earlier, observations could have been made under disturbed dynamo conditions (Blanc and Richmond 1980; Fejer et al. 2017). Westward motion of the ionospheric irregularities are known to occur during disturbed dynamo (Abdu et al. 2003; Paulino et al. 2010), and therefore, our observations confirm the occurrence of low-latitude disturbances.

\section{Discussion}

\section{On June solstice radar echoes}

The detection of $F$-region echoes during the observation campaign is in good agreement with previous radar studies of June solstice $F$-region irregularities (Patra et al. 2009; Yokoyama et al. 2011; Guozhu et al. 2012; Otsuka et al. 2012). Using the Gadanki radar, for instance, Patra et al. (2009) found that the $F$-region echoes occurred every night during a 20-day observational campaign in July/August 2008 when solar activity was extremely low $($ F10.7 $=61$ SFU $)$. Additional observations carried out at other low-latitude sites confirmed the occurrence of June solstice irregularities during low solar flux conditions 
(Otsuka et al. 2009; Otsuka et al. 2012; Yokoyama et al. 2011; Guozhu et al. 2012).

Even though the solar flux conditions during our campaign were higher than those during the Gadanki campaign, we were still able to observe a number of irregularity events. More importantly, we were able to detect events occurring late at night, which allowed us to examine the bottomside dynamics using an airglow all-sky camera. Late-night June solstice events have been observed before. Most of the events observed by Patra et al. (2009), for instance, occurred in the post-midnight sector. Yokoyama et al. (2011), Otsuka et al. (2009, 2012), and $\mathrm{Li}$ et al. (2012) also reported events that occurred after local midnight. They used VHF radar observations of meter-scale irregularities made at low magnetic latitudes while our UHF observations of sub-meter irregularities were made at the magnetic equator.

We must point out that some of our June solstice ESF events occurred under geomagnetically disturbed conditions as indicated by the AE index (see Figs. 1 and 3). Therefore, favorable conditions for GRT instability development during those events could have been produced by disturbance electric fields. We have, nevertheless, also found cases of ESF development under geomagnetically quiet conditions. On July 30 and 31, for instance, ESF was observed despite a long period of quiet $\mathrm{AE}$ index.

\section{On the airglow signatures of bottomside perturbations}

The airglow observations, described in the previous section, show the occurrence of ionospheric perturbations at bottomside $F$-region heights. We found the fluctuations to be localized, occurring within only a few degrees of longitude. When two low-intensity airglow bands were observed simultaneously, the spacing between them was about $350-460 \mathrm{~km}$. Previous observations of large-scale wave structures (LSWS) made by the ALTAIR incoherent scatter radar indicated a zonal wavelength between 340 and $870 \mathrm{~km}$ (Tsunoda and White 1981; Tsunoda et al. 2011). The initial faint airglow perturbations associated with the bottomside fluctuations (see Figs. 4, 5, and 6) show zonal motion. ALTAIR observations of LSWS, however, show a near-stationary growth (Tsunoda 2005). Using measurements of the ionospheric electron content (TEC) made by ground-based receivers and beacon signals from low Earth orbit (LEO) satellites, Tsunoda et al. (2011) and Tulasi Ram et al. (2014) found TEC perturbations prior to ESF development that they associated with LSWS. A statistical study carried out by Tulasi Ram et al. (2014) showed that the TEC LSWS had zonal wavelengths varying between 100 and $700 \mathrm{~km}$ with most cases having a wavelength ranging between 200 and $500 \mathrm{~km}$.

The low-intensity airglow bands we observed were along the NS direction. Since the magnetic declination at Jicamarca is close to zero, the observations indicate that the phase fronts of the airglow perturbations are aligned with the magnetic meridian. Using TEC measuremens made by latitudinally spaced ground-based receivers, Tsunoda et al. (2011) showed an example where the TEC perturbations associated with LSWS were also aligned with the magnetic field. Tulasi Ram et al. (2014) showed additional examples of TEC fluctuations associated with magnetic field-aligned LSWSs.

A number of physical mechanisms can be considered for the origin of bottomside fluctuations that are seen as faint airglow fluctuations. Those include electron density perturbations produced by atmospheric gravity waves (AGW) (Makela et al. 2010), sporadic- $E$ layers (Tsunoda 2007), collisional shear instability (Hysell and Kudeki 2004), and electrified traveling ionospheric disturbances (TIDs) (Miller et al. 2009). Another scenario that must be considered as well is that the faint airglow fluctuations are signatures of the early-stage development of ESF events. Nevertheless, the airglow observations are likely to represent the manifestation of initial perturbations leading to ESF. More importantly, perhaps, is that those disturbances manifest well ahead (as early as hour in advance) of ESF appearance. Note this is also in agreement with the time it took between the detection of LSWS and the observation of fully developed ESF events made by ALTAIR (Tsunoda and White 1981).

\section{On bottomside perturbations and ESF}

The comparison between radar and airglow observations (Figs. 4, 5, and 6) indicates a relationship between airglow features and the development of ESF. In order to provide further evidence of this relationship, we used the E-W scans made by AMISR-14 for August 3-4 to create two-dimensional "images" of the scattering structures in the magnetic equatorial plane. The images are similar to those produced by Rodrigues et al. (2015) but with better angular coverage because of the larger number of beam directions. We then combined the AMISR-14 images with airglow measurements for a direct comparison of the observations.

Figure 7 shows the results of combining twodimensional airglow and radar observations. The top panel shows, again, the RTI map for the night of August $3-4$. The vertical red lines indicate times when airglow observations are available and can be compared with radar measurements. The bottom panels show the zonal scans in the magnetic equatorial plane made by AMISR14 at the times indicated in the RTI map. For a direct comparison of variations in longitude, we also show the mean airglow intensity (solid red line) around the latitude of Jicamarca for each time.

As described in the previous section, the August 3-4 observations show a small-amplitude airglow perturbation right above Jicamarca (see also Fig. 6) as early as 21:41 
LT. The zonal scans made by AMISR-14 allow us to determine, without spatial ambiguity, that radar echoes do not accompany the observed airglow perturbation. The lack of radar echoes indicates the occurrence of an airglow perturbation prior to ESF development. Figure 7 shows that only around 22:28 LT bottomside echoes start to be observed to the east of the radar site. As the airglow structure moves to the west, the echoing region develops vertically indicating the development of an ESF depletion.

Figure 8 shows, for completeness, additional snapshots of airglow and radar observations for August 3-4. Two small plumes can be identified: one at 23:00 LT and another at 23:40 LT. The radar scans also show that, around 23:00 LT, the zonal motion of the ESF structure changes direction, from westward to eastward.

The ESF events observed by AMISR developed well after sunset hours when the PRE is known to occur. Therefore, the ESF events developed despite the absence of the large vertical drifts associated with the PRE. Unfortunately, plasma drift measurements were not available for this campaign, but climatological analysis of ISR drift measurements at Jicamarca shows weak vertical drifts for the period (Scherliess and Fejer 1999; Smith et al. 2016). The digisonde observations (see Fig. 2) also do not provide evidence of large, long-lasting upward $F$-region uplifts for the three events discussed here. We must point out that Abdu et al. (2009) and Tsunoda (2010) have already presented cases where typical ESF could be observed despite a weak local PRE peak.

\section{On ionospheric TEC signatures of ESF}

The total electron content (TEC) measurements made by a collocated dual-frequency GPS receiver provide, yet, additional evidence that initial airglow fluctuations were due to density perturbations confined to bottomside heights. TEC depletions only developed about an hour after the faint airglow perturbations are detected and when $F$-region echoes (plumes) were detected by AMISR-14. Figure 9 shows a comparison of the airglow measurements with GPS TEC observations. The top two rows of panels show airglow snapshots for August 3-4, 2016. The red markers show the tracks of the ionospheric piercing points (IPP) of GPS signals (at $350 \mathrm{~km}$ altitude). The tracks are for \pm 8 minutes within the time indicated for each image. The satellite identifier (Pseudo-Random Noise (PRN)) is shown at the beginning of each track.

The bottom panel of Fig. 9 shows the vertical TEC for PRNs 21, 25, 29, and 24. Satellites 21, 25, and 29 were

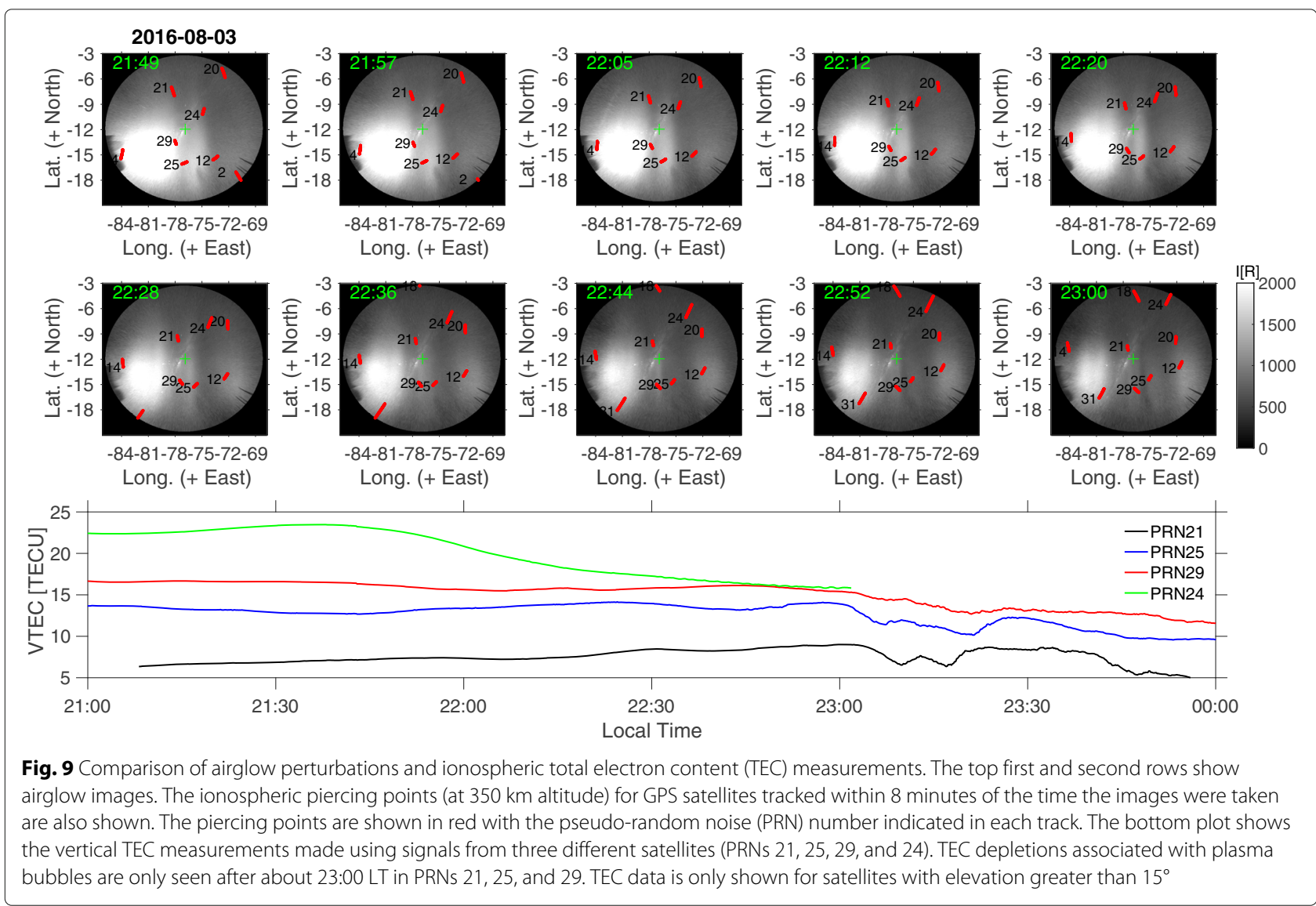


selected because the signal IPPs intercept, and nearly follow, the zonal motion of the westernmost airglow perturbation that is observed above Jicamarca at the beginning of the sequence of airglow images. PRN 24 was selected because it crosses the easternmost airglow perturbation between 21:49 and 22:36 LT. The GPS observations confirm that ESF depletions are only present after 23:00 LT, when radar plumes are also first observed by the AMISR14. PRNs 21 and 25 show (more clearly than PRN 29) TEC depletions between 23:00 and 23:30 LT. PRN 24 does not show indication of depletions after 23:00 LT because it had already moved to the east of the perturbations by that time. The TEC curves for PRNs 21, 25, and 29 also show short-period fluctuations that are indicative of small-scale irregularities within the large-scale ESF depletion.

\section{Conclusions}

A number of studies using VHF coherent backscatter radar observations outside the American sector found an unexpected high occurrence of ionospheric $F$-region irregularities during low solar flux June solstice (e.g., Patra et al. 2009; Otsuka et al. 2009, 2012; Li et al. 2011, 2012; Yokoyama et al. 2011). These geophysical conditions are believed to be unfavorable for the development of generalized Rayleigh-Taylor instabilities responsible for equatorial spread- $F$ (ESF).

We report results of multi-instrumented experimental efforts to better specify the occurrence of June solstice ESF in the American sector and to better understand the conditions prior to their development. As part of this effort, we used measurements made by a 14-panel version of the Advanced Modular Incoherent Scatter Radar (AMISR-14) system. Our results include the first UHF radar observations of June solstice ESF events over the Jicamarca Radio Observatory $\left(11.95^{\circ} \mathrm{S}, 76.87^{\circ} \mathrm{W}, \sim 1^{\circ}\right.$ dip latitude).

The AMISR-14 observations show that June solstice echoes can be detected in either the pre-midnight or postmidnight sector. The observations also show nights when echoes occurred on both pre- and post-midnight sectors. This is similar to what has been observed by other VHF radars at different longitude sectors (e.g., Patra et al. 2009). We point out, however, that unstable $F$-region conditions during our campaign of observations could have been produced by disturbance electric fields of magnetospheric origin for at least some of the events. The AE index shows some level of geomagnetic activity at high latitudes during most of the days when ESF was observed. There are, however, at least 2 days (July 30 and 31, 2016) when ESF occurred during quiet geomagnetic conditions.

The late appearance (22:00 LT or later) of three events observed during our campaign provided a unique opportunity to investigate the equatorial bottomside $F$-region conditions, prior to ESF, using nighttime airglow measurements. Airglow observations prior to typical, early evening ESF are difficult, particularly in the magnetic equatorial region. The airglow measurements $(630 \mathrm{~nm}$, red line) made by a collocated all-sky camera indicate the occurrence of ionospheric bottomside $F$-region perturbations as early as 1 hour prior to the detection of ESF echoes.

The observed airglow perturbations show some of the features of the so-called large-scale wave structures (LSWS) that have been observed, previously, using the ALTAIR incoherent scatter radar (e.g., Tsunoda and White 1981) and ground-based TEC measurements (Tsunoda et al. 2011; Tulasi Ram et al. 2014). The bottomside fluctuations have zonal wavelenghts between 300 and $500 \mathrm{~km}$, are aligned with the magnetic meridian, and extend at least a few degrees in magnetic latitude. Additionally, the airglow fluctuations grow in amplitude and then coincide with fully developed ESF structures observed by AMISR-14. Collocated GPS ionospheric TEC measurements indicate that the initial airglow fluctuations associated with ionospheric density perturbations confined to bottomside $F$-region heights. TEC depletions only appear when radar echoes reach the main $F$-region and topside heights. While a number of physical mechanisms can be considered for the origin of the airglow fluctuations, they should represent, nevertheless, the manifestation of initial bottomside disturbances leading to ESF.

Future work includes the collection of additional AMISR-14 F-region measurements jointly with airglow observations. Additional measurements will allow us to investigate whether or not faint airglow perturbations, such as those presented here, are always followed by ESF. Current work on determining the main spatial features of airglow depletions observed by the Jicamarca imager has already been started. The collocated radar-airglow observations will also provide an observational benchmark for which numerical models of ESF could be tested. For instance, realistic numerical models of ESF should be able to produce electron density perturbations that, when used as inputs of airglow models, reproduce the observed (temporal and spatial) variations in airglow intensity.

\section{Acknowledgements}

GPS TEC measurements used in this study were kindly provided by Dr. Jade Morton from the University of Colorado, Boulder (jade.morton@colorado.edu).

\section{Funding}

Work at UT Dallas was supported by NSF (AGS-1554926) and AFOSR

(FA9550-13-1-0095). Work at Boston University was supported by NSF (AGS-1552301 and AGS-1123222). The Jicamarca Radio Observatory is a facility of the Instituto Geofisico del Peru operated with support from the NSF AGS-1433968 through Cornell University. Work at Ana G. Mendez University System was supported by NSF (AGS-1039593).

\section{Authors' contributions}

FSR proposed the topic and observations, analyzed the measurements, and wrote the report. MM helped with setting up the AMISR-14 radar mode and made the auxiliary measurements available. DAH and CRM maintain the all-sky 
digital camera system at Jicamarca and helped with the interpretation of airglow measurements. BGF helped with the data interpretation. WZ collaborated with the corresponding author in the preparation of the results and manuscript. JFA is the principal investigator for AMISR-14. All authors read and approved the final manuscript.

\section{Competing interests}

The authors declare that they have no competing interests.

\section{Publisher's Note}

Springer Nature remains neutral with regard to jurisdictional claims in published maps and institutional affiliations.

\section{Author details}

${ }^{1}$ W. B. Hanson Center for Space Sciences, UT Dallas, 800 W. Campbell Rd, Richardson, TX, 75080, USA. ${ }^{2}$ Center for Space Sciences, Boston University, 725 Commonwealth Avenue, Boston 02215, USA. ${ }^{3}$ Utah State University, Old Main Hill, Logan 84322, USA. ${ }^{4}$ Jicamarca Radio Observatory, Apartado 13-0207, Peru. ${ }^{5}$ Ana G. Mendez University System, Avenida Ana G. Mendez, San Juan 00926, Puerto Rico.

\section{Received: 31 August 2017 Accepted: 9 February 2018}

Published online: 01 March 2018

\section{References}

Abdu MA, Bittencourt JA, Batista IS (1981) Magnetic declination control of the equatorial $F$ region dynamo electric field development and spread F. J Geophys Res Space Phys 86(A13):11443-11446. https://doi.org/10.1029/ JA086iA13p11443

Abdu MA, Batista IS, Takahashi H, MacDougall J, Sobral JH, Medeiros AF, Trivedi NB (2003) Magnetospheric disturbance induced equatorial plasma bubble development and dynamics: a case study in brazilian sector. J Geophys Res Space Phys 108(A12). https://doi.org/10.1029/ 2002JA009721. 1449

Abdu MA, Alam Kherani E, Batista IS, de Paula ER, Fritts DC, Sobral JHA (2009) Gravity wave initiation of equatorial spread F/plasma bubble irregularities based on observational data from the spreadfex campaign. Ann Geophys 27(7):2607-2622. https://doi.org/10.5194/angeo-27-2607-2009

Ajith KK, Ram ST, Yamamoto M, Yokoyama T, Gowtam VS, Otsuka Y, Tsugawa T, Niranjan K (2015) Explicit characteristics of evolutionary-type plasma bubbles observed from equatorial atmosphere radar during the low to moderate solar activity years 2010-2012. J Geophys Res Space Phys 120(2):1371-1382. https://doi.org/10.1002/2014JA020878. 2014JA020878

Ajith KK, Tulasi Ram S, Yamamoto M, Otsuka Y, Niranjan K (2016) On the fresh development of equatorial plasma bubbles around the midnight hours of june solstice. J Geophys Res Space Phys 121(9):9051-9062. https://doi.org/ 10.1002/2016JA023024. 2016JA023024

Aveiro HC, Hysell DL (2010) Three-dimensional numerical simulation of equatoria F region plasma irregularities with bottomside shear flow. J Geophys Res Space Phys 115(A11). https://doi.org/10.1029/2010JA015602. A11321

Blanc M, Richmond AD (1980) The ionospheric disturbance dynamo. J Geophys Res Space Phys 85(A4):1669-1686. https://doi.org/10.1029/ JA085iA04p01669

Chapagain NP, Fejer BG, Chau JL (2009) Climatology of postsunset equatorial spread f over Jicamarca. J Geophys Res Space Phys 114(A7). https://doi. org/10.1029/2008JA013911. A07307

Eccles JV, St. Maurice JP, Schunk RW (2015) Mechanisms underlying the prereversal enhancement of the vertical plasma drift in the low-latitude ionosphere. J Geophys Res Space Phys 120(6):4950-4970. https://doi.org/ 10.1002/2014JA020664. 2014JA020664

Fejer BG, Scherliess L, de Paula ER (1999) Effects of the vertical plasma drift velocity on the generation and evolution of equatorial spread F. J Geophys Res Space Phys 104(A9):19859-19869. https://doi.org/10.1029/ 1999JA900271

Fejer BG (2011) Low latitude ionospheric electrodynamics. Space Sci Rev 158(1):145-166. https://doi.org/10.1007/s11214-010-9690-7

Fejer BG, Blanc M, Richmond AD (2017) Post-storm middle and low-latitude ionospheric electric fields effects. Space Sci Rev 206(1):407-429. https:// doi.org/10.1007/s11214-016-0320-x

Guozhu L, Ning B, Liu L, Wan W, Hu L, Zhao B, Patra AK (2012) Equinoctial and June solstitial F-region irregularities over Sanya. IJRSP 41(2):184-198
Hickey DA, Martinis CR, Rodrigues FS, Varney RH, Milla MA, Nicolls MJ, Strømme A, Arratia JF (2015) Concurrent observations at the magnetic equator of small-scale irregularities and large-scale depletions associated with equatorial spread F. J Geophys Res Space Phys 120(12):10883-10896. https://doi.org/10.1002/2015JA021991. 2015JA021991

Hysell DL, Burcham JD (2002) Long term studies of equatorial spread F using the JULIA radar at Jicamarca. J Atmos Solar Terr Phys 64(12):1531-1543. https://doi.org/10.1016/S1364-6826(02)00091-3. Equatorial Aeronomy

Hysell DL, Kudeki E (2004) Collisional shear instability in the equatorial F region ionosphere. J Geophys Res Space Phys 109(A11). https://doi.org/10.1029/ 2004JA010636. A11301

Kelley MC, Pfaff R, Baker KD, Ulwick JC, Livingston R, Rino C, Tsunoda R (1982) Simultaneous rocket probe and radar measurements of equatorial spread F-transitional and short wavelength results. J Geophys Res Space Phys 87(A3):1575-1588. https://doi.org/10.1029/JA087iA03p01575

Li G, Ning B, Abdu MA, Yue X, Liu L, Wan W, Hu L (2011) On the occurrence of postmidnight equatorial $F$ region irregularities during the June solstice. J Geophys Res Space Phys 116(A4). https://doi.org/10.1029/2010JA016056. A04318

Makela JJ, Ledvina BM, Kelley MC, Kintner PM (2004) Analysis of the seasonal variations of equatorial plasma bubble occurrence observed from Haleakala, hawaii. Ann Geophys 22(9):3109-3121. https://doi.org/10.5194/ angeo-22-3109-2004

Makela JJ, Vadas SL, Muryanto R, Duly T, Crowley G (2010) Periodic spacing between consecutive equatorial plasma bubbles. Geophys Res Lett 37(14). https://doi.org/10.1029/2010GL043968. L14103

McClure JP, Hanson WB, Hoffman JH (1977) Plasma bubbles and irregularities in the equatorial ionosphere. J Geophys Res 82(19):2650-2656. https://doi. org/10.1029/JA082i019p02650

Miller ES, Makela JJ, Kelley MC (2009) Seeding of equatorial plasma depletions by polarization electric fields from middle latitudes: experimental evidence. Geophys Res Lett 36(18). https://doi.org/10.1029/2009GL039695. L18105

Otsuka Y, Shiokawa K, Ogawa T, Yokoyama T, Yamamoto M, Fukao S (2004) Spatial relationship of equatorial plasma bubbles and field-aligned irregularities observed with an all-sky airglow imager and the equatorial atmosphere radar. Geophys Res Lett 31(20). https://doi.org/10.1029/ 2004GL020869. L20802

Otsuka Y, Ogawa T, Effendy (2009) VHF radar observations of nighttime F-region field-aligned irregularities over Kototabang, Indonesia. Earth, Planets Space 61(4):431-437. https://doi.org/10.1186/BF03353159

Otsuka Y, Shiokawa K, Nishioka M (2012) VHF radar observations of post-midnight F-region field-aligned irregularities over Indonesia during solar minimum. Indian J Radio Sp Phys 41:199-207

Patra AK, Phanikumar DV, Pant TK (2009) Gadanki radar observations of F region field-aligned irregularities during June solstice of solar minimum: first results and preliminary analysis. J Geophys Res Space Phys 114(A12) https://doi.org/10.1029/2009JA014437. A12305

Paulino I, Medeiros AF, Buriti RA, Sobral JHA, Takahashi H, Gobbi D (2010) Optical observations of plasma bubble westward drifts over brazilian tropical region. J Atmos Solar Terr Phys 72(5):521-527. https://doi.org/10 1016/j.jastp.2010.01.015

Rodrigues FS, de Paula ER, Abdu MA, Jardim AC, Iyer KN, Kintner PM, Hysell DL (2004) Equatorial spread F irregularity characteristics over São Luís, Brazil using VHF radar and GPS scintillation techniques. Radio Sci. 39(RS1S31)

Rodrigues FS, Nicolls MJ, Milla MA, Smith JM, Varney RH, Strømme A, Martinis C, Arratia JF (2015) Amisr-14: observations of equatorial spread F. Geophys Res Lett 42(13):5100-5108. https://doi.org/10.1002/ 2015GL064574. 2015GL064574

Saito S, Maruyama T (2007) Large-scale longitudinal variation in ionospheric height and equatorial spread F occurrences observed by ionosondes. Geophys Res Lett. 34(16). https://doi.org/10.1029/2007GL030618. L16109

Saito S, Fukao S, Yamamoto M, Otsuka Y, Maruyama T (2008) Decay of 3-m-scale ionospheric irregularities associated with a plasma bubble observed with the equatorial atmosphere radar. J Geophys Res. 113(A11318)

Scherliess L, Fejer BG (1997) Storm time dependence of equatorial disturbance dynamo zonal electric fields. J Geophys Res Space Phys 102(A11):24037-24046. https://doi.org/10.1029/97JA02165

Scherliess L, Fejer BG (1999) Radar and satellite global equatorial F region vertical drift model. J Geophys Res Space Phys 104(A4):6829-6842. https:// doi.org/10.1029/1999JA900025 
Smith JM, Rodrigues FS, de Paula ER (2015) Radar and satellite investigations of equatorial evening vertical drifts and spread F. Ann Geophys 33(11):1403-1412. https://doi.org/10.5194/angeo-33-1403-2015

Smith JM, Rodrigues FS, Fejer BG, Milla MA (2016) Coherent and incoherent scatter radar study of the climatology and day-to-day variability of mean $F$ region vertical drifts and equatorial spread F. J Geophys Res Space Phys 121 (2):1466-1482. https://doi.org/10.1002/2015JA021934. 2015JA021934

Sultan PJ (1996) Linear theory and modeling of the Rayleigh-Taylor instability leading to the occurrence of equatorial spread F. J Geophys Res Space Phys 101(A12):26875-26891. https://doi.org/10.1029/96JA00682

Thampi SV, Yamamoto M, Tsunoda RT, Otsuka Y, Tsugawa T, Uemoto J, Ishii M (2009) First observations of large-scale wave structure and equatorial spread F using CERTO radio beacon on the C/NOFS satellite. Geophys Res Lett 36(18). https://doi.org/10.1029/2009GL039887. L18111

Tulasi Ram S, Yamamoto M, Tsunoda RT, Thampi SV, Gurubaran S (2012) On the application of differential phase measurements to study the zonal large scale wave structure (LSWS) in the ionospheric electron content. Radio Sci 47(2). https://doi.org/10.1029/2011RS004870. RS2001

Tulasi Ram S, Yamamoto M, Tsunoda RT, Chau HD, Hoang TL, Damtie B, Wassaie M, Yatini CY, Manik T, Tsugawa T (2014) Characteristics of large-scale wave structure observed from African and Southeast Asian longitudinal sectors. J Geophys Res Space Phys 119(3):2288-2297. https:// doi.org/10.1002/2013JA019712. 2013JA019712

Tsunoda RT, White BR (1981) On the generation and growth of equatorial backscatter plumes: 1. Wave structure in the bottomside F layer. J Geophys Res Space Phys 86(A5):3610-3616. https://doi.org/10.1029/ JA086iA05p03610

Tsunoda RT (1983) On the generation and growth of equatorial backscatter plumes: 2. Structuring of the west walls of upwellings. J Geophys Res Space Phys 88(A6):4869-4874. https://doi.org/10.1029/JA088iA06p04869

Tsunoda, RT (1985) Control of the seasonal and longitudinal occurrence of equatorial scintillations by the longitudinal gradient in integrated $\mathrm{E}$ region Pedersen conductivity. J Geophys Res Space Phys 90(A1):447-456. https:// doi.org/10.1029/JA090iA01 p00447

Tsunoda RT (2005) On the enigma of day-to-day variability in equatorial spread F. Geophys Res Lett 32(8). https://doi.org/10.1029/2005GL022512. L08103

Tsunoda, RT (2007) Seeding of equatorial plasma bubbles with electric fields from an Es-layer instability. J Geophys Res Space Phys 112(A6). https://doi. org/10.1029/2006JA012103. A06304

Tsunoda RT, Bubenik DM, Thampi SV, Yamamoto M (2010) On large-scale wave structure and equatorial spread $\mathrm{F}$ without a post-sunset rise of the $\mathrm{F}$ layer. Geophys Res Lett 37(7). https://doi.org/10.1029/2009GL042357. L07105

Tsunoda RT, Yamamoto M, Tsugawa T, Hoang TL, Tulasi Ram S, Thampi SV, Chau HD, Nagatsuma T (2011) On seeding, large-scale wave structure, equatorial spread F, and scintillations over Vietnam. Geophys Res Lett 38(20). https://doi.org/10.1029/2011GL049173. L20102

Woodman RF, La Hoz C (1976) Radar observations of F region equatorial irregularities. J Geophys Res 81(31):5447-5466. https://doi.org/10.1029/ JA081i031p05447

Woodman RF (2009) Spread F-an old equatorial aeronomy problem finally resolved? Ann Geophys 27(5):1915-1934. https://doi.org/10.5194/angeo27-1915-2009

Yokoyama T, Yamamoto M, Otsuka Y, Nishioka M, Tsugawa T, Watanabe S, Pfaff RF (2011) On postmidnight low-latitude ionospheric irregularities during solar minimum: 1. Equatorial atmosphere radar and GPS-TEC observations in Indonesia. J Geophys Res Space Phys 116(A11). https://doi. org/10.1029/2011JA016797. A11325

\section{Submit your manuscript to a SpringerOpen ${ }^{\circ}$ journal and benefit from:}

- Convenient online submission

- Rigorous peer review

- Open access: articles freely available online

- High visibility within the field

- Retaining the copyright to your article

Submit your next manuscript at $\gg$ springeropen.com 